\title{
Nodular lymphoid hyperplasia: A thin grey zone between hyperplasia and Pathological aggregate
}

\author{
Singh B.M.K ${ }^{1}$, Bishnu $\mathbf{A}^{2}$, Shetty $\mathbf{T}^{3}$, Shetty $\mathbf{P}^{4}$ \\ ${ }^{1}$ Dr Brij Mohan Kumar Singh, Department of Immunohematology \& Blood Transfusion, Kasturba Medical College, \\ Manipal, Manipal University, ${ }^{2}$ Dr Arijit Bishnu, ${ }^{3}$ Dr Tanvi Shetty, ${ }^{4}$ Dr Panna Shetty, ${ }^{2,3,4}$ All authors are affiliated with \\ Department of Pathology, Melaka Manipal Medical College, Manipal Campus, Manipal University, India
}

Address for Correspondence: Dr Brij Mohan Kumar Singh, Department of Immunohematology \& Blood Transfusion, Kasturba Medical College, Manipal, Manipal University, India. E-mail- drbrijkumar@ gmail.com

\begin{abstract}
Introduction: The clinical-pathological characteristics of 12 patients with intestinal nodular lymphoid hyperplasia $(\mathrm{NLH})$ are described with the aim to try and delineate between hyperplasia and pathological aggregate of lymphoid tissue in the intestine and its association with other diseases from Indian subcontinent. Materials and Method: 12 diagnosed cases of NLH were retrieved out of 2256 intestinal punch biopsy done at our centre and were evaluated as per histological criteria laid down by various authors including their clinical and pathological features. Results: Most frequent symptom includes diarrhoea and weight loss and the severity of these symptoms were directly proportional to the number and location of the lymphoid nodules. Prominent lymphoid nodules in mucosa and/or submucosa were documented histologically in all cases. One patient had associated common variable immunodeficiency which on follow up developed intestinal lymphoid malignancy of NHL type (DLBCL) and the other was having hypogammaglobulinemia. All cases showed absence of plasma cells, except one with predominant symptoms of Gastroesophageal reflux disease (GERD) rather than diarrhea. Conclusion: NLH runs as a benign course, but these cases should be followed up with histology as well as thorough clinical and biochemical evaluation to detect early lymphoma that can be managed efficiently.
\end{abstract}

Keyword: Nodular lymphoid hyperplasia, Common variable immunodeficiency, Non Hodgkin lymphoma.

\section{Introduction}

Nodular lymphoid hyperplasia (NLH) is an uncommon histological findings in small bowel characterized by markedly hyperplastic mitotically active germinal center with well demarcated lymphocyte mantle zone [1]. The lymphoid nodules can be present in the mucosa and submucosa; and can be seen in any portion of the gastrointestinal tract, more commonly in the small bowel [2,3]. Endoscopically NLH can be seen as raised lesions or may sometime resemble polyp which are commonly seen in patients with common variable immunodeficiency and infection with human immunodeficiency virus [4].

Literature and experience by authors suggests close follow up of cases with NLH as these patients clinically as well as morphologically bears a risk of developing

Manuscript received: $17^{\text {th }}$ September 2016

Reviewed: $28^{\text {th }}$ September 2016

Author Corrected: $15^{\text {th }}$ October 2016

Accepted for Publication: $30^{\text {th }}$ October 2016 intestinal and extra-intestinal lymphoma [5]. NLH is usually seen in pediatric age group but adults are not spared. It usually runs a benign and self-limiting course in children whereas in adults the prognosis is uncertain [6].

\section{Materials and Method}

12 cases of NLH were retrieved from the archives of Department of Pathology, Kasturba Hospital, Manipal from January 2012 to January 2016. All the paraffin embedded blocks, hematoxylin and eosin ( $\mathrm{H} \& \mathrm{E})$ slides were retrieved and re-evaluated to see if they all follow the histopathology criteria viz. hyperplastic lymphoid follicles, mitotically active germinal centers and well demarcated lymphocyte mantle localized in mucosa and/or submucosa. While performing the histopathological re-evaluation following features were considered viz. number and localization of lymphoid 
follicles, type and severity of inflammation in the lamina propria, and presence of villous atrophy/ blunting. All the $\mathrm{H} \& \mathrm{E}$ slides with faint staining or having poor quality were discarded and assessment was done on freshly cut sections from the paraffin embedded blocks.
For clinical and laboratory data, patient's hospital records were searched and following parameters were evaluated - age, duration and type of symptoms, weight loss, hemoglobin, mean corpuscular volume (MCV), total protein, albumin, globulin, human immunedeficiency virus antibody and stool examination report for ova and cysts of parasites.

\section{Result}

A total of 2256 small bowel punch biopsies were done since January 2012 till January 2016, of which only 12 cases were diagnosed as NLH. All these cases were males with a median age of 21 years (7 to 43 years). Duration of symptoms ranged from 1 to 16 months. After evaluating the clinical data, we found that the predominant manifestation among these patients were diarrhea and weight loss (Table 1). The data on weight loss was subjective and the same was monitored on follow up of these patients. All patients along with the other symptoms had associated abdominal pain. One patient had presented with gastro-esophageal reflux disease (GERD) with no history of diarrhea or weight loss.

All diagnosed cases of NLH were re-evaluated following the histological criteria using light microscope. In six cases hyperplastic lymphoid follicles were present in the mucosa (Table 2). Only one patient was showing more than two hyperplastic lymphoid follicles.

Table-1: Symptom and sign of patients with NLH.

\begin{tabular}{|c|c|}
\hline Signs \& symptoms & N (12 cases) \\
\hline Diarrhea & 11 \\
\hline Weight loss & 11 \\
\hline Abdominal pain & 12 \\
\hline Lymphadenopathy & 01 \\
\hline Pallor & 10 \\
\hline Chronic cough & 01 \\
\hline Arthralgia & 01 \\
\hline Neuropthy & Nil \\
\hline
\end{tabular}

Table-2: Mucosal biopsies from patient with NLH

\begin{tabular}{|l|c|}
\hline Abnormality & N (12 cases) \\
Localization of lymphoid follicles & 06 \\
- Mucosa & 02 \\
- Submucosa & 04 \\
- Mucosa + Submucosa & \\
\hline Inflammatory changes seen in lamina propria & 11 \\
- Lymphocyte-plasma cells & 01 \\
- Plasma cells & 08 \\
- Lymphocyte & 04 \\
- Eosinophils & 21 \\
\hline Villous atrophy & 11 \\
- Partial & NIL \\
\hline Total & 08 \\
\hline Increased intraepithelial lymphocyte & 04 \\
\hline Crypt hyperplasia & 04 \\
\hline
\end{tabular}


It was noted that patient with mixed (mucosa and submucosa) hyperplastic lymphoid follicles have lower hemoglobin concentration as compared to only mucosal or submucosal localization. Only one patient with symptom of GERD had plasma cell infiltration in lamina propria. Predominant inflammatory infiltrate seen was lymphocyte, with four cases were lymphocyte was associated with eosinophil were seen.

Partial villous atrophy was noted in 11 cases and it was well associated with the weight loss and low globulin levels than those without villous atrophy. One case was having near normal mucosal lining.

Among all cases of NLH only one patient was associated with common variable immunodeficiency (CVI). None of the patients showed infestation by any parasites with repeated stool examinations on follow up. One case with common variable immunodeficiency was found to have intestinal lymphoma of NHL type (diffuse large B-cell) DLBCL type with very high Ki67 index (Fig 2, Fig 3, Fig 4) on follow up after 3 years of the diagnosis of NLH. Three cases had been screened for HIV antibody, which yielded negative result.

\section{Discussion}

Nodular lymphoid hyperplasia (NLH) is a rare pathological entity which is associated with increased risk for gastrointestinal malignancies, mainly Non Hodgkin lymphoma. Earlier studies have described NLH in immunocompromised as well as immunocompetent patients [1-5]. The rarity of this lesion can be understood by its incidence among large number of small bowel biopsies done at our center. We have followed the histological criteria described by various authors to label these cases as NLH. We also know from the literature that there is a thin grey zone present between normal lymphoid follicles becoming pathological. There is no strict definition or criteria available to delineate normal lymphoid tissue from hyperplastic, or for hyperplasia becoming pathological [7], even though we described NLH based on criteria discussed by various authors [8].

We have reported 10 cases of NLH in ileum and two in duodenum, which were in accordance with many authors which emphasized the frequent location of NLH in jejunum-ileum [1-3]. The pathogenesis of NLH is idiopathic, but it is proposed that due to the maturation defect in the B-cell there is accumulation of plasma cell precursor to compensate dysfunctional intestinal lymphoid tissue [9]. Due to these dysfunctional intestinal lymphoid tissues, patients are more prone for recurrent parasite infection. It was suggested by various studies that Giardia lamblia is one of the commonest infection seen in these cases [10]. We were unable to demonstrate any parasite in stool or on microscopy, although we had one case with hypogammaglobinemia and one case with common variable immunodeficiency who presented with NLH. It would have been possible to pick up parasitic infection by Giardia lamblia if we had used fecal ELISA technique to detect the parasite. But again for a country like India, where over the counter medicines are readily available as an empirical therapy for chronic diarrhea, the chances to detect these parasites are grim. It was also proposed by many authors about the possible link of Helicobacter pylori (H. pylori) infection with NLH [11,12]. Patients on anti H. Pylori therapy do respond positively and show marked regression of the lesions as compared to the patients with persistent $\mathrm{H}$. pylori infection [13].

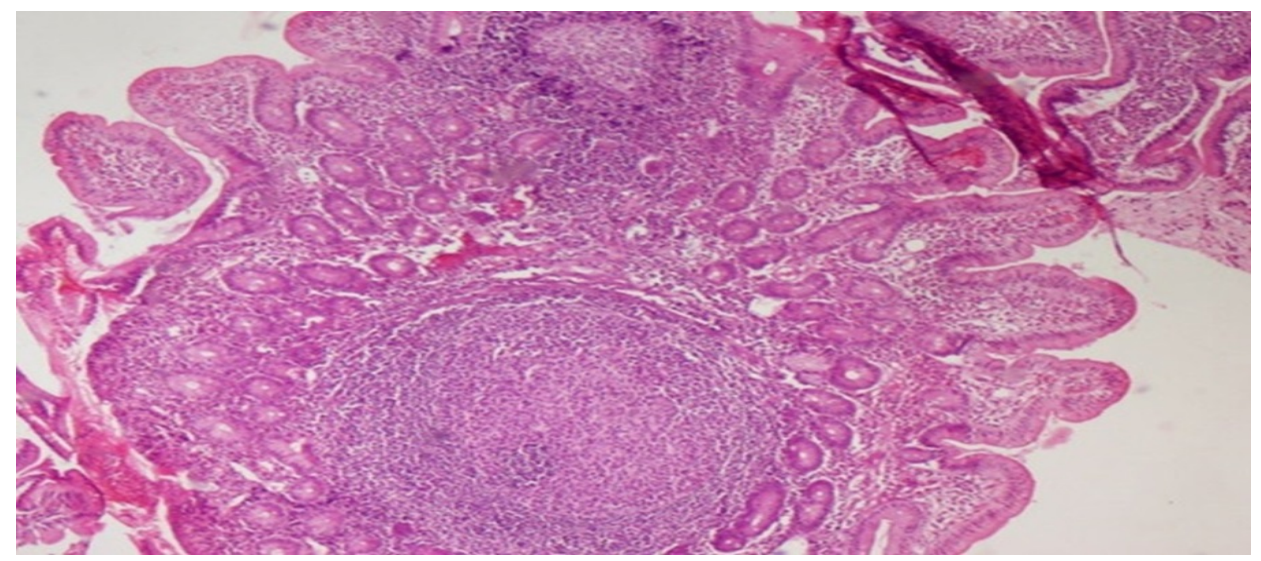

Figure-1: H \& E X200 Lymphoid follicles with prominent germinal center 


\section{Research Article}

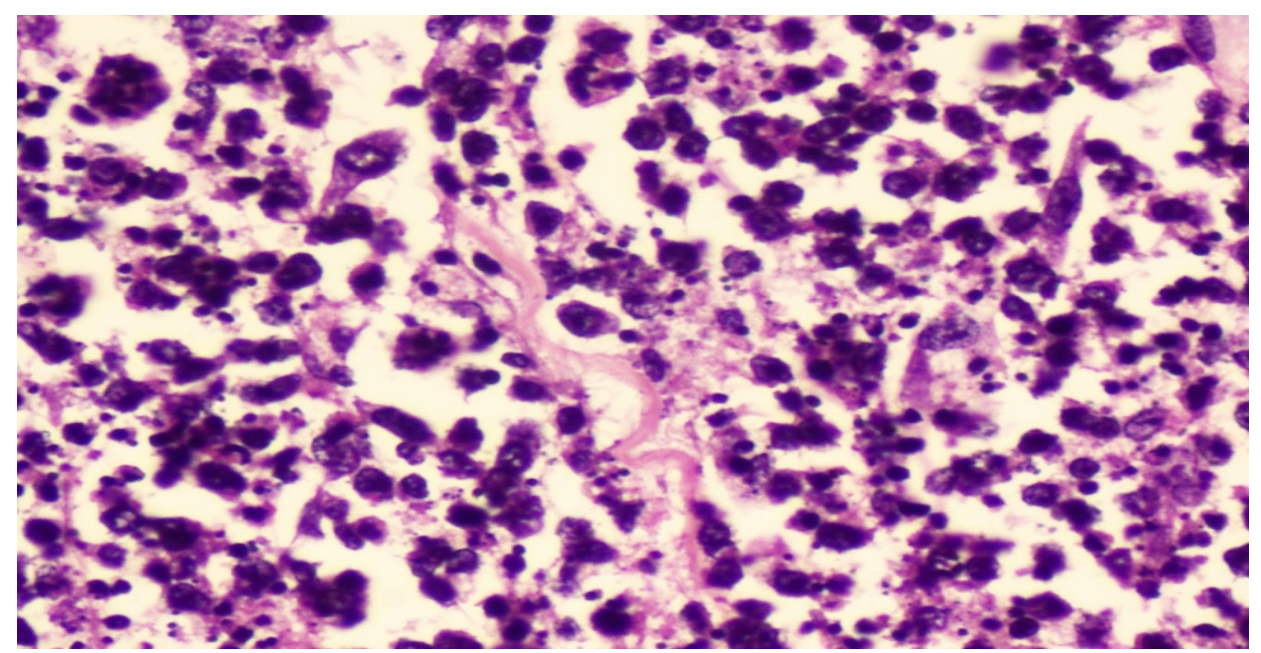

Figure-2: H\&E X400 Malignant lymphoid cells with bizzare forms

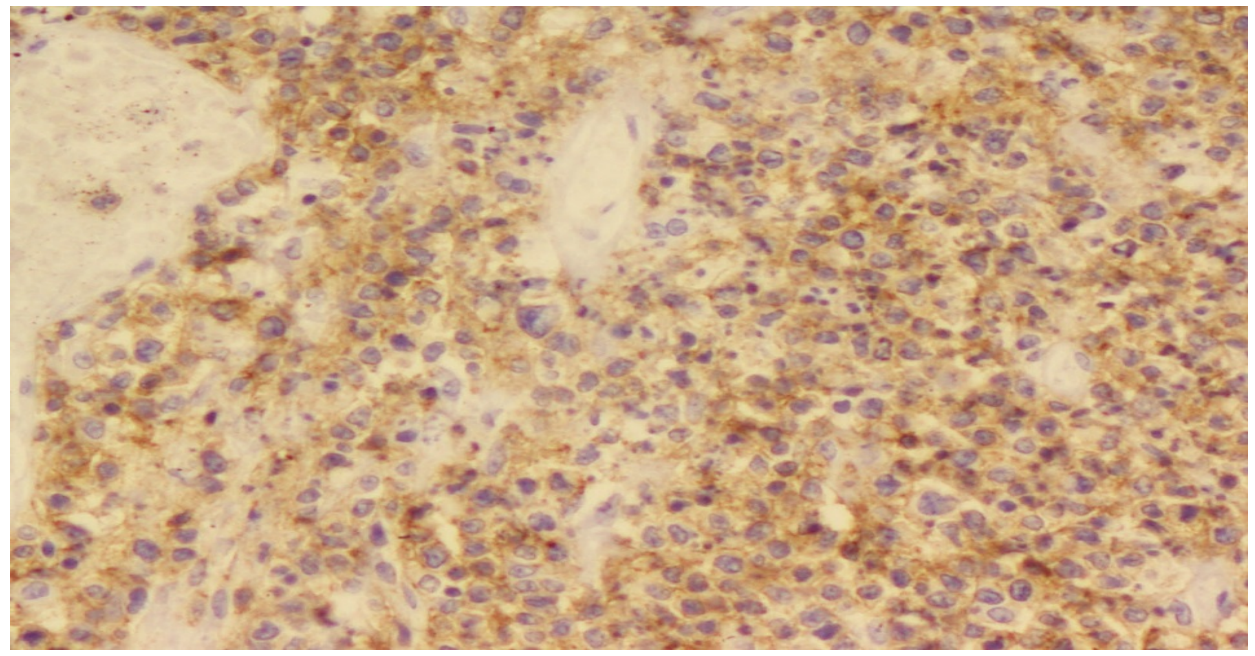

Figure-3:Lymphoid cells positive for leucocyte common antigen, X 200

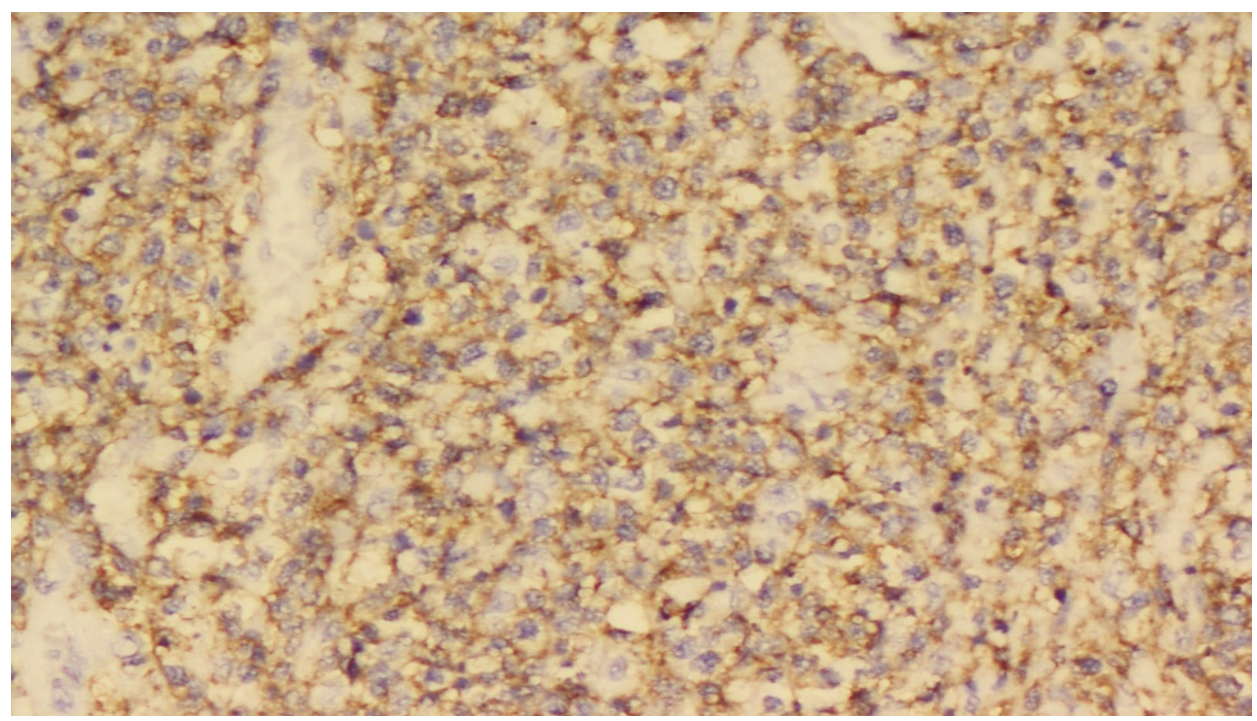

Figure-3: Lymphoid cells positive for CD20, X200 
Research Article

Histologically, the number of lymphoid follicles with mitotically active germinal centre is not the diagnostic criteria [1,2]. We found majority of the cases presenting with 1-2 hyperplastic lymphoid follicles in the mucosa. Patient who had more number of lymphoid follicles showed more marked weight loss, low hemoglobin and very low MCV as compared to patients who had less number of follicles and located in mucosa and/or submucosa. All these patients presented clinically as chronic diarrhea.

Literature clearly depicts the association of NLH with various organic conditions $[10,14,15]$. We found only one case with common variable immunodeficiency (CVI) which on follow up presented as diffuse large B cell lymphoma (DLBCL) in the intestine. CVI in itself is a complex of decreased serum immunoglobulin, gastrointestinal dysmotility, sino-pulmonary infection and most of these patients develop malignancies in due course of time. Overall all patients with NLH are at an increased risk of developing lymphoid malignancy in the gastrointestinal tract. It has been suggested by various studies that extra-intestinal site for lymphoid malignancy is not rare. Rubio tapia et al[16] has described Hodgkin's disease in the mediastinum, Jonsson et al[5] has reported extra-intestinal lymphoma with NLH, where hyperplastic lymphoid tissue was completely cured after chemotherapy with remission of lymphoma and then reappeared at relapse. In our study all cases were on close follow up since diagnosis of NLH, and only one case developed lymphoid malignancy.

We have also observed partial villous atrophy, increased intraepithelial lymphocyte and crypt hyperplasia in our study as prominent features seen in association with NLH as described by other authors.

Inspite of many theories of various conditions related to $\mathrm{NLH}$, there are various case reports in the literature where no associated conditions have been described, and the diagnosis is made on histo-morphological evaluation alone[17,18,19].

\section{Conclusion}

There are several missing links in NLH, such as epidemiological data and non-invasive method to follow up such cases. Although NLH runs a benign course in pediatric as well as adult patients, close follow up with histopathology is warranted in all cases as they bear increased risk of developing lymphoid malignancy. Parasitic infections if detected has to be tackled efficiently in-order to minimize the risk of malabsorption.

Funding: Nil, Conflict of interest: None initiated, Permission from IRB: Yes

\section{References}

1. Rambaud JC, De Saint-Louvent P, Marti R, Galian A, Mason DY, Wassef M, Licht H, Valleur P, Bernier JJ. Diffuse follicular lymphoid hyperplasia of the small intestine without primary immunoglobulin deficiency. Am J Med. 1982 Jul;73(1):125-32.

2. Ranchod M, Lewin KJ, Dorfman RF. Lymphoid hyperplasia of the gastrointestinal tract. A study of 26 cases and review of the literature. Am J Surg Pathol. 1978 Dec;2(4):383-400.

3. Case records of the Massachusetts General Hospital. Weekly clinicopathological exercises. Case 8-1997. A 65-year-old man with recurrent abdominal pain for five years. N Engl J Med. 1997 Mar 13;336(11):786-93. DOI: 10.1056/NEJM199703133361108.

4. Levendoglu H, Rosen Y. Nodular lymphoid hyperplasia of gut in HIV infection. Am J Gastroenterol. 1992 Sep;87(9):1200-2.

5. Jonsson OT, Birgisson S, Reykdal S. Resolution of nodular lymphoid hyperplasia of the gastrointestinal tract following chemotherapy for extraintestinal lymphoma. Dig Dis Sci 2002; 47: 2463-2465

6. Ward EM, Wolfsen HC. Review article: the noninherited gastrointestinal polyposis syndromes. Aliment Pharmacol Ther 2002; 16: 333-342 [PMID: 11876685 DOI: 10.1046/ j.1365-2036.2002.01172.x]

7. Riddell RH, Petras RE, Williams GT, Sobin LH. Lymphoproliferative disorders of the intestines. In: Riddell RH, Petras RE, Williams GT, Sobin LH, eds. Tumors of the Intestines. Washington, DC: Armed Forces Institute of Pathology; 2003: 395-430. Atlas of Tumor Pathology; 3rd series, fascicle 32.

8. Alberto Rubio-Tapia, Jorge Hernández-Calleros, Sagrario Trinidad-Hernández, Luis Uscanga. Clinical characteristics of a group of adults with nodular lymphoid hyperplasia: A single center experience. World J Gastroenterol 2006 March 28; 12(12): 19451948. 
9. Hermans PE, Diaz-Buxo JA, Stobo JD. Idiopathic late-onset immunoglobulin deficiency. Clinical observations in 50 patients. Am J Med. 1976 Aug;61 (2):221-37.

10. de Weerth A, Gocht A, Seewald S, Brand B, van Lunzen J, Seitz U, Thonke F, Fritscher-Ravens A, Soehendra N. Duodenal nodular lymphoid hyperplasia caused by giardiasis infection in a patient who is immunodeficient. Gastrointest Endosc 2002; 55: 605607 [PMID: 11923787 DOI: 10.1067/ mge.2002. 120786]

11. Khuroo MS, Khuroo NS, Khuroo MS. Diffuse duodenal nodular lymphoid hyperplasia: a large cohort of patients etiologically related to Helicobacter pylori infection. BMC Gastroenterol 2011; 11: 36 [PMID: 21481240 DOI: $10.1186 / 1471-230 X-11-36]$

12. Misra SP, Misra V, Dwivedi M, Singh PA. Helicobacter pylori-induced lymphonodular hyperplasia: a new cause of gastric outlet obstruction. J Gastroenterol Hepatol 1998; 13: 1191-1194 [PMID: 9918424 DOI: 10.1111/j.1440-1746.1998. tb00603.x]

13. Andreia Albuquerque Nodular lymphoid hyperplasia in the gastrointestinal tract in adult patients: A review World J Gastrointest Endosc 2014 November 16; 6(11): 534-540

14. Cooper MD, Schoerder HW. Primary immune deficiency diseases. In: Kasper DL, ed. Harrison's Principles of Internal Medicine, 16th ed. McGraw-Hill, 2005: 1939-1947.
15. Matuchansky C, Touchard G, Lemaire M, Babin P, Demeocq F, Fonck Y, Meyer M, Preud'Homme JL. Malignant lymphoma of the small bowel associated with diffuse nodular lymphoid hyperplasia. N Engl J Med. 1985 Jul 18;313(3):166-71. DOI: 10.1056/ NEJM 198507183130307

16. Rubio CA. Nonprotruding colorectal neoplasms: epidemiologic viewpoint. World J Surg. 2000 Sep;24 (9): 1098-103. DOI: 10.1007/s002680010147.

17. Rambaud JC, De Saint-Louvent P, Marti R, Galian A, Mason DY, Wassef M, Licht H, Valleur P, Bernier JJ. Diffuse follicular lymphoid hyperplasia of the small intestine without primary immunoglobulin deficiency. Am J Med 1982; 73: 125-132 [PMID: 7091167 DOI: 10.1016/0002-9343(82)90938-X]

18. Monsanto P, Lérias C, Almeida N, Lopes S, Cabral JE, Figueiredo P, Silva M, Julião M, Gouveia H, Sofia C. Intestinal nodular lymphoid hyperplasia and extraintestinal lymphoma--a rare association. Acta Gastroenterol Belg. 2012 Jun;75(2):260-2.

19. Matuchansky C, Touchard G, Lemaire M, Babin P, Demeocq F, Fonck Y, Meyer M, Preud'Homme JL. Malignant lymphoma of the small bowel associated with diffuse nodular lymphoid hyperplasia. N Engl J Med. 1985 Jul 18;313(3):166-71. DOI: 10.1056/ NEJM 198507183130307.

\section{How to cite this article?}

Singh B.M.K, Bishnu A, Shetty T, Shetty P. Nodular lymphoid hyperplasia: A thin grey zone between hyperplasia and Pathological aggregate.Trop J Path Micro 2016;2(3):104-109.doi: 10.17511/jopm.2016.i03.05 